\title{
Minor adverse events during thoracoscopic pulmonary lobectomy
}

\author{
Dario Amore ${ }^{1}$, Marcellino Cicalese ${ }^{1}$, Roberto Scaramuzzi ${ }^{1}$, Davide Di Natale ${ }^{1}$, Alessandro Izzo ${ }^{2}$, Pasquale \\ Imitazione $^{3}$, Antonio Molino ${ }^{3}$, Carlo Curcio ${ }^{1}$ \\ ${ }^{1}$ Division of Thoracic Surgery, Monaldi Hospital, Naples, Italy; ${ }^{2}$ Division of Pneumology, San Giuseppe Moscati Hospital, Avellino, Italy; ${ }^{3}$ Division \\ of Pneumology, Monaldi Hospital, University of Naples Federico II, Naples, Italy \\ Contributions: (I) Conception and design: D Amore; (II) Administrative support: D Amore, C Curcio; (III) Provision of study materials or patients: C \\ Curcio, D Amore, M Cicalese, A Molino, A Izzo; (IV) Collection and assembly of data: D Amore, R Scaramuzzi, D Di Natale, P Imitazione; (V) Data \\ analysis and interpretation: D Amore, R Scaramuzzi, D Di Natale, P Imitazione, A Izzo; (VI) Manuscript writing: All authors; (VII) Final approval of \\ manuscript: All authors. \\ Correspondence to: Dario Amore. Division of Thoracic Surgery, Monaldi Hospital, Leonardo Bianchi street, 1, 80131 Naples, Italy. \\ Email: dario.amore@alice.it.
}

\begin{abstract}
Several authors have reported major complications during thoracoscopic pulmonary lobectomy but a few papers have been published concerning minor adverse events. This definition in our report takes into account no life-threatening intraoperative complications managed with minimal invasive approach and with no need for conversion to thoracotomy. We retrospectively reviewed 644 patients who underwent thoracoscopic anatomic pulmonary lobectomy between April 2011 and May 2018: among these, 25 patients suffered minor intraoperative complications such as bronchial injury, stapler failure during parenchymal resection, injury to bronchial artery, oozing from vascular stump, etc. Our findings suggest that these complications don't adversely affect the early postoperative outcomes but they still need proper management to avoid major intraoperative complications and an eventful postoperative course. The report shows that minor adverse events may occur for device malfunction but, in some instances, human errors or inadequate knowledge of technological instruments may be implicated.
\end{abstract}

Keywords: Video-assisted thoracoscopic surgery lobectomy (VATS lobectomy); adverse event; minor bleeding

Received: 27 June 2018; Accepted: 23 July 2018; Published: 14 August 2018.

doi: 10.21037 /jovs.2018.07.25

View this article at: http://dx.doi.org/10.21037/jovs.2018.07.25

\section{Introduction}

In recent decades several data have demonstrated the advantages of video-assisted thoracoscopic surgery (VATS) lobectomy, compared with the open approach, as a shorter hospital stay and a more rapid return to preoperative activity, especially in elderly patients and those with poor pulmonary function (1-3). However, even patients undergoing minimally invasive procedures for pulmonary lobectomy are exposed to a complex set of potential intraoperative complications. While many authors have analyzed major complications during video-assisted thoracoscopic anatomical lung resections (4-6), only a few papers have been published concerning minor adverse events. The aim of the present review was to analyze minor complications that occurred during VATS lobectomy in a single-institutional retrospective study. Our experience suggests that standardization of a technique is mandatory to reduce the possibility of surgical errors; at the same time, because endoscopic instruments such as staplers and vessel sealers are indispensable for VATS, we argue that surgeons must avoid the so called "knowledge gap" through the continuous update on the use and technological advances of devices.

\section{Patients and methods}

At our institution, between April 2011 and May 2018, 644 patients underwent thoracoscopic anatomic pulmonary lobectomy for known or suspected lung cancer. Pulmonary 


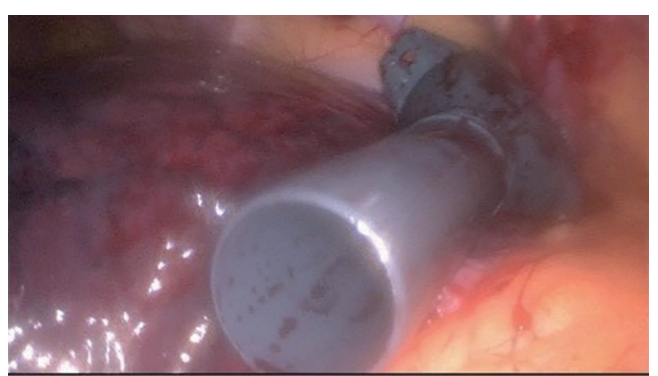

Figure 1 Thoracoport fallen accidentally into pleural cavity at the end of procedure, after insertion through the utility incision for general thoracoscopic inspection of the thoracic cavity.

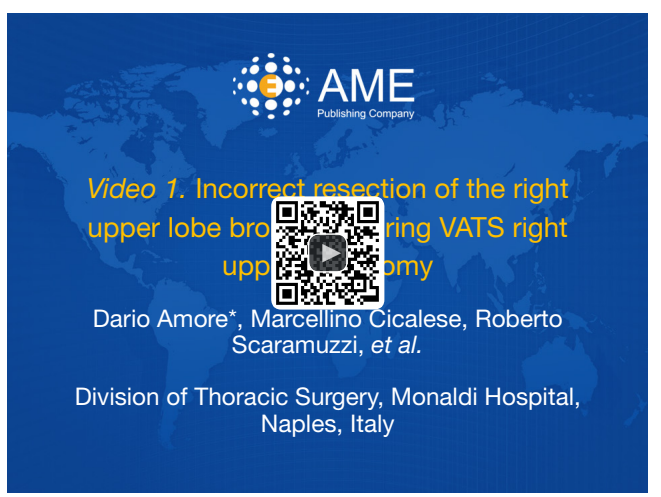

Figure 2 Incorrect resection of the right upper lobe bronchus during VATS right upper lobectomy (7). The video shows a stapler with a not curved tip while accidentally cutting only the cartilage wall of the bronchus. VATS, video-assisted thoracoscopic surgery. Available online: http://www.asvide.com/article/view/26340

resection was performed under general anesthesia using one-lung ventilation with the patient in lateral decubitus position. In all cases we adopted a three-port anterior approach with individual division of the bronchovascular structures and systematic lymph node dissection if the frozen section indicated malignancy, using a 30-degree thoracoscope and, without rib spreading, only the vision of a monitor. Mechanical staplers were very useful in dividing hilar structures and fissures, while an effective closure of small-diameter pulmonary vessels was gained by energy based surgical instruments. At the end of each procedure, specimen retrieval was performed using an endobag. We defined as minor adverse events during VATS lobectomy those no life-threatening intraoperative complications managed with minimally invasive accesses and with no need for conversion to thoracotomy.

\section{Results}

Among 644 patients, minor adverse events during VATS lobectomy occurred in 25 patients and were the following: bronchial injury [3], stapler failure during parenchymal resection [3], injury to bronchial artery [3], oozing from vascular stump [1], partial dehiscence of vascular stump [1], internal mammary artery injury [2], bleeding from utility incision or access incision [7], introduction of camera into abdominal cavity [1], foreign bodies fallen into the pleural cavity [4] (Figure 1). Bronchial injuries occurred during right upper lobectomy: in two cases we performed a direct suture for the membranous part of the stump of the right upper lobe bronchus that showed a tear caused by stapler with a not curved tip. In another case there was an unintentional passage of stapler between the membranous part and the cartilaginous wall of the right upper lobe bronchus and a further stapler bronchial closure, under the stapled line, was necessary (Figure 2). Oozing from vascular stump came from an anterior ascending arterial branch and was caused by the retraction of lung parenchyma and hilar structures during right upper lobectomy: it was controlled through application of titanium clip. Partial dehiscence of vascular stump occurred during middle lobectomy: at the end of the procedure a bleeding began at the edge of middle lobe vein stump, closed by a stapler, when the suction device came in contact with the vessel. The adverse event was managed through application of hem-o-lok clip. Internal mammary artery injury happened in two patients undergoing right lower lobectomy and where the utility incision extension, to extract resected specimen, was need (Table 1). In all cases patients had an uneventful postoperative course and were discharged after the fourthfifth day without any complication.

\section{Discussion}

As major bleeding, even minor bleeding during VATS lobectomy requires a methodical approach to an effective intraoperative management. Whenever a such complication is encountered, the first step, if necessary, is to quickly clean the scope lens and focus attention on the origin of the bleeding (Figure 3). The next step is to apply a method of tamponade that may include sponges on a clamp or stick, use of the adjacent lung parenchyma to compress injury or suction compression. In this case, the use of the suction device is also helpful for blood removal and to better expose the operative field. In some instances, as bleeding from small blood vessels or vascular stump, titanium or hem-o- 
Table 1 Summary of intraoperative minor adverse events

\begin{tabular}{lcc}
\hline Type of resection & Minor adverse event & Management \\
\hline RUL & Bronchial injury & Direct suture or additional stapler firing \\
RUL & Stapler failure during parenchymal resection & Additional stapler firing \\
LUL, RLL & Injury to bronchial artery & Electrocoagulation \\
RUL & Oozing from vascular stump & Titanium clip application \\
ML & Partial dehiscence of vascular stump & Hem-o-lok clip application \\
RLL & Internal mammary artery injury & Electrocoagulation \\
RUL, RLL, LLL & Bleeding from utility incision or access incision & Electrocoagulation \\
RLL & Introduction of camera into abdominal cavity & Access site closure \\
RUL, RLL, LUL & Foreign bodies fallen into pleural cavity & Video-guided recovery
\end{tabular}

RUL, right upper lobectomy; LUL, left upper lobectomy; RLL, right lower lobectomy; ML, middle lobectomy; LLL, left lower lobectomy.

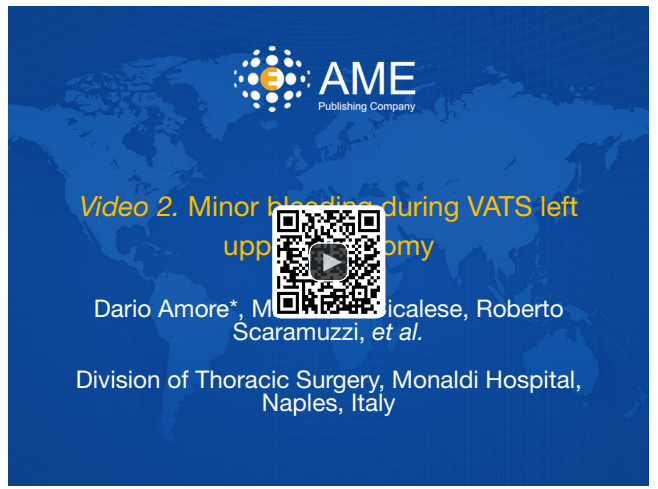

Figure 3 Minor bleeding during VATS left upper lobectomy (8). The video shows an unintentional injury to a bronchial artery during dissection by the suction device. After cleaning the endoscope, the adverse event is managed through a quick electrocoagulation. VATS, video-assisted thoracoscopic surgery.

Available online: http://www.asvide.com/article/view/26341

lok clips may be used but this strategy requires that some principles be followed: sufficient surface to secure the clip at the base of the vessel, cautious application to the bleeding site because misplacement could cause further vascular injury, not recommended use if it is necessary to divide any remaining hilar structures in that area because later tissue manipulation can avulse the clips. Another option for haemorrhage control is application of topical haemostatic agents whose effectiveness is aided, in case of minor bleeding, by low pressure of both the pulmonary arterial and venous systems (3). If these options aren't sufficient to bleeding control, it can be helpful to use other strategies such as

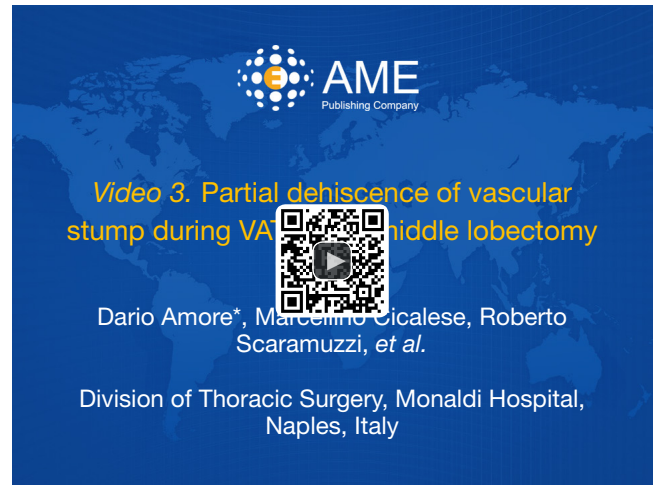

Figure 4 Partial dehiscence of vascular stump during VATS right middle lobectomy (10). The video shows a bleeding coming from the proximal stump of the middle lobe vein after vascular transection using endovascular stapling. VATS, video-assisted thoracoscopic surgery.

Available online: http://www.asvide.com/article/view/26342

the SCAT (suction-compressing angiorrhaphy technique) method that ranges from direct suture upon suction compression of the injured site, for defects of less than 5 $\mathrm{mm}$, to clamping the proximal artery with an atraumatic instrument with subsequent thoracoscopic suture repair, for defects that exceed one third of the circumference of the vessel (9). In our experience, among the causes of bleeding, is reported a partial dehiscence of vascular stump due to a possible stapler-tissue thickness mismatch (Figure 4): this is among the adverse events of pulmonary vascular stapling reported in literature, as well as laceration of adjacent vessels or stapling failure (2). In case of bleeding originating from 

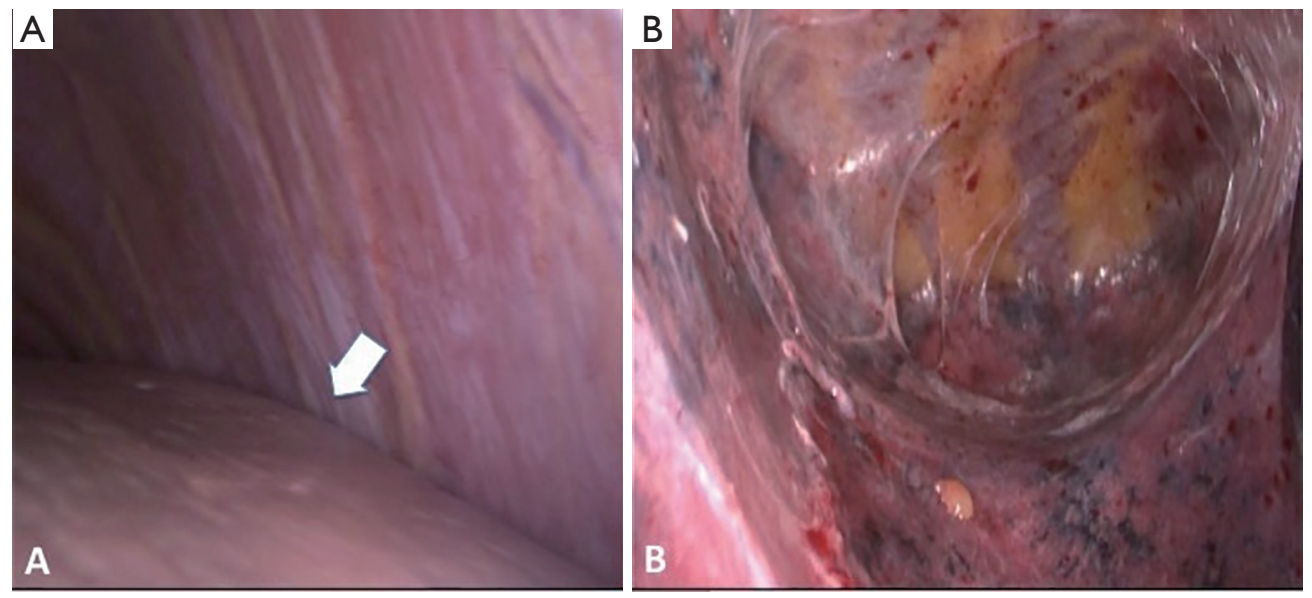

Figure 5 Incorrect thoracoport placement during anterior three-port right lower lobectomy. (A) Accidental introduction of thoracoscope into the abdominal cavity with liver visualization (white arrow); (B) subsequent inspection of the right pleural cavity with evidence of extensive pleural adhesions.

a vascular stump, some authors recommend a repair with a suture below the stapler line (11) although sometimes, especially at the end of the operation, it may be sufficient to apply a clip. Another cause of bleeding linked to our experience has been an oozing from the stump of a segmental branch of the pulmonary artery closed by a bipolar vesselsealing device and probably subjected to excessive tension during the retraction of other hilar structures. Although the use of bipolar vessel-sealings has been proved to be effective and safe for closure of vessels up to $7 \mathrm{~mm}$ in diameter, in some instances, especially in presence of thick pulmonary arteries or in absence of adequate working space on both sides of the vascular structure, a ligation of the proximal site of vessel with a suture or a twice sealing before cutting might be useful $(1,12,13)$. Actually, stapling devices greatly facilitate major pulmonary resections in VATS but several intraoperative complications during vascular or bronchial division can be related to the use of endostaplers. In our case, the injuries after transecting the right upper lobe bronchus during right upper lobectomy were perhaps linked to the use of a stapler with straight anvils that usually don't pass around tubular structures as well as angled instruments. To overcome this limitation, authors have proposed a red rubber catheter or penrose drain to guide the anvil, or silk sutures or vessel loops to maximize the space for anvil passage (14). Although nowadays the introduction of staplers with curved tips is more useful for the approach to bronchovascular structures, we recommend, however, to be cautious and never try to overcome resistances with direct pressure to pass the staplers. Finally, whenever a VATS lobectomy is planned through a three-port anterior approach, we recommend, according to other authors, to make first the utility incision in the midaxillary line in the fourth or fifth intercostal space (15): this strategy allows to avoid a wrong access into the abdominal cavity (Figure $5 A, B$ ), looking for the level of the diaphragm that can be raised in some circumstances as pleural adhesions, obesity and restrictive lung disease. At the end of the surgical procedure, it is advisable, moreover, to always inspect the minimally invasive accesses, especially the utility incision after eventual extension for specimen retrieval, because even minor injuries to the chest wall can lead to postoperative hemothorax.

\section{Conclusions}

Although the learning curve for VATS lobectomy is essential to gain improvement of technical skills and surgical outcomes, major complications as well as minor adverse events represent an inevitable part of thoracoscopic major lung resections. Their knowledge, as well as keeping up with technological progress, can help reduce human and device-related errors. In the family of complications, minor adverse events are like younger children but a wise parent knows that all children deserve the same attention.

\section{Acknowledgments}

Funding: None. 


\section{Footnote}

Conflicts of Interest: All authors have completed the ICMJE uniform disclosure form (available at http://dx.doi. org/10.21037/jovs.2018.07.25). The authors have no conflicts of interest to declare.

Ethical Statement: The authors are accountable for all aspects of the work in ensuring that questions related to the accuracy or integrity of any part of the work are appropriately investigated and resolved. All procedures performed in studies involving human participants were in accordance with the Helsinki Declaration (as revised in 2013). Written informed consent was obtained from the patient for publication of this manuscript and any accompanying images.

Open Access Statement: This is an Open Access article distributed in accordance with the Creative Commons Attribution-NonCommercial-NoDerivs 4.0 International License (CC BY-NC-ND 4.0), which permits the noncommercial replication and distribution of the article with the strict proviso that no changes or edits are made and the original work is properly cited (including links to both the formal publication through the relevant DOI and the license). See: https://creativecommons.org/licenses/by-nc-nd/4.0/.

\section{References}

1. Shah RD, D'Amico TA. Modern impact of video assisted thoracic surgery. J Thorac Dis 2014;6:S631-6.

2. Yano M, Takao M, Fujinaga T, et al. Adverse events of pulmonary vascular stapling in thoracic surgery. Interact Cardiovasc Thorac Surg 2013;17:280-4.

3. Igai H, Kamiyoshihara M, Ibe T, et al. Troubleshooting for bleeding in thoracoscopic anatomic pulmonary resection. Asian Cardiovasc Thorac Ann 2017;25:35-40.

4. Decaluwe H, Petersen RH, Hansen H, et al. Major intraoperative complications during video-assisted thoracoscopic anatomical lung resections: an intention-totreat analysis. Eur J Cardiothorac Surg 2015;48:588-98; discussion 599.

5. Yang J, Xia Y, Yang Y, et al. Risk factors for major adverse events of video-assisted thoracic surgery lobectomy for lung cancer. Int J Med Sci 2014;11:863-9.

6. Liang C, Wen H, Guo Y, et al. Severe intraoperative complications during VATS Lobectomy compared with thoracotomy lobectomy for early stage non-small cell lung cancer. J Thorac Dis 2013;5:513-7.

7. Amore D, Cicalese M, Scaramuzzi R, et al. Incorrect resection of the right upper lobe bronchus during VATS right upper lobectomy. Asvide 2018;5:668. Available online: http://www.asvide.com/article/view/26340

8. Amore D, Cicalese M, Scaramuzzi R, et al. Minor bleeding during VATS left upper lobectomy. Asvide 2018;5:669.

Available online: http://www.asvide.com/article/ view/26341

9. Xiao ZL, Mei JD, Pu Q, et al. Technical strategy for dealing with bleeding during thoracoscopic lung surgery. Ann Cardiothorac Surg 2014;3:213-5.

10. Amore D, Cicalese M, Scaramuzzi R, et al. Partial dehiscence of vascular stump during VATS right middle lobectomy. Asvide 2018;5:670. Available online: http:// www.asvide.com/article/view/26342

11. Scarci M, Gonzalez-Rivas D, Schmidt J, et al. Management of Intraoperative Difficulties During Uniportal VideoAssisted Thoracoscopic Surgery. Thorac Surg Clin 2017;27:339-46.

12. Toishi M, Yoshida K, Agatsuma H, et al. Usefulness of vessel-sealing devices for $\leq 7 \mathrm{~mm}$ diameter vessels: a randomized controlled trial for human thoracoscopic lobectomy in primary lung cancer. Interact Cardiovasc Thorac Surg 2014;19:448-55.

13. White A, Kucukak S, Lee DN, et al. Energy-Based Ligation of Pulmonary Vessels: A Six-Year Experience With Ultrasonic Shears in Video-Assisted Thoracoscopic Lobectomy and Segmentectomy. Ann Thorac Surg 2016;101:1334-7.

14. Demmy TL, James TA, Swanson SJ, et al. Troubleshooting video-assisted thoracic surgery lobectomy. Ann Thorac Surg. 2005;79:1744-52; discussion 1753.

15. Hansen HJ, Petersen RH. Video-assisted thoracoscopic lobectomy using a standardized three-port anterior approach - The Copenhagen experience. Ann Cardiothorac Surg 2012;1:70-6.

doi: $10.21037 /$ jovs.2018.07.25

Cite this article as: Amore D, Cicalese M, Scaramuzzi R, Di Natale D, Izzo A, Imitazione P, Molino A, Curcio C. Minor adverse events during thoracoscopic pulmonary lobectomy. J Vis Surg 2018;4:170. 